\title{
Vitamin D Concentrations are Decreased in Patients with Alopecia Areata
}

\author{
Nigar Yilmaz ${ }^{1 *}$, Gamze Serarslan² and Cumaali Gokce ${ }^{3}$
}

${ }^{1}$ Department of Biochemistry, Faculty of Medicine, Mugla University, Mugla, Turkey

${ }^{2}$ Department of Dermatology, Faculty of Medicine, Mustafa Kemal University, Hatay, Turkey

${ }^{3}$ Department of Endocrinology, Faculty of Medicine, Mustafa Kemal University, Hatay, Turkey

\begin{abstract}
Vitamin D has been of increased interest in the role of maintaining immune system balance. Alopecia Areata (AA) is a T-cell mediated autoimmune disease which causes anagen-stage hair follicles. Low concentration of vitamin $D$ may be a risk factor for AA. We aimed to determine vitamin $D$ concentrations in patients with AA. 25-hydroxyvitamin $D(25(\mathrm{OH})-\mathrm{D})$ concentrations and 1,25 dihydroxyvitamin $\mathrm{D} 3\left(1,25(\mathrm{OH})_{2} \mathrm{D}_{3}\right)$ were determined from sera collected from patients with $A A(n=42)$ and healthy controls $(n=42) .25(\mathrm{OH})-\mathrm{D}$ and $1,25(\mathrm{OH})_{2} \mathrm{D}_{3}$ concentrations were measured by ELISA method. The concentrations of both $25(\mathrm{OH})-\mathrm{D}$ and $1,25(\mathrm{OH})_{2} \mathrm{D}_{3}$ were found to be significantly lower in patients with AA than control group ( $p<0.001$ for each analysis). The results show that there is a significant difference between AA patients and normal subjects in terms of serum vitamin $D$ concentrations. Therefore, it is suggested that vitamin $D$ deficiency may have a role in the setting of $A A$.
\end{abstract}

Keywords: Alopesia areata; 25-hydroxyvitamin D; 1,25-dihydroxyvitamin D3; Autoimmune disease; Vitamin D deficiency

\section{Introduction}

Vitamin D is known as a pro-hormone which is primarily synthesized in the skin. After synthesis, vitamin D which is biologically inactive, binds Vitamin D-Binding Protein (DBP) and transports to the liver where it is hydroxylated to 25-Hydroxyvitamin D (25(OH)-D). 1-alpha-hydroxylase (1a-OHase) enzyme converts $25(\mathrm{OH})$-D to 1,25 -dihydroxyvitamin $\mathrm{D} 3\left(1,25(\mathrm{OH})_{2} \mathrm{D}_{3}\right)$ in the kidney [1]. Inadequate vitamin D concentrations lead to osteoporosis and muscle weakness, especially in elderly. Recently, vitamin $\mathrm{D}$ has been found to have immunoregulatory effects. $1,25(\mathrm{OH})_{2} \mathrm{D}_{3}$ which is the major form of vitamin $\mathrm{D}$, is a modulator of immune function including activities of T-lymphocytes and B-lymphocytes as well as having role on immune responses [2-4]. The concentration of $1,25(\mathrm{OH})_{2} \mathrm{D}_{3}$ depends on an adequate supply of circulating 25(OH)-D which is described as the primary indicator of vitamin D status [4] Vitamin $\mathrm{D}$ deficiency was established as a risk factor for occurrence of some autoimmune diseases [5,6]. Alopecia areata (AA) is an autoimmune disease which is characterized by hair loss and affects any hair-bearing area [7]. AA has features caused by CD41 and CD81 T cells targeting hair follicles as an autoimmune-mediated skin disease. The immune system attacks to hair follicles in patients with alopesia areata. On the other hand, it was reported that $1,25(\mathrm{OH})_{2} \mathrm{D}_{3}$ have an important role in hair follicle biology. The developing of hair follicle depends on the Vitamin D Receptor (VDR) expression which correlates with increased differentiation of the follicle keratinocytes. The corepressor hairless (Hr) has been studied in the epidermis. The lack of the $\mathrm{Hr}$ causes of VDR results in alopesia. Hair follicles may be cause of vitamin D defiency. The pathophysiology of AA has not been fully understood. We hypothesized that vitamin $\mathrm{D}$ deficiency may be a risk factor for development of AA.

\section{Methods}

\section{Subjects}

Informed consents of all patients and healthy controls were obtained according to the Declaration of Helsinki. Patients with AA were selected from patients who were treated in the dermatology clinic of Mustafa Kemal University between the months of June and September of 2010. There is no variation in vitamin D concentration depending of the season of the year in Turkey. The study was approved by the local Ethics Committee of Mustafa Kemal University (Hatay,
Turkey). Patients were subjected to full medical history including, dietary intake of vitamin $\mathrm{D}$, personal and family history of comorbid autoimmune disorder and also examined dermatologically. The amount of daily vitamin D products and supplements were asked. Control group and patients who had normal renal and liver function with no vitamin $\mathrm{D}$ or calcium steroid medication history were included in the study. Especially control group who have any systemic disorder and autoimmune disorder subjected in our study. We asked especially the patient and control groups who have the same factors (including BMI, no smoking, lifestyle). Fourty-two patients (28 female and 14 male) with extensive forms of AA (patchy, ophiasis, totalis) and 42 healthy control subjects (29 female and 13 male) were analyzed in the present study. There was no significant difference between patients with AA $(31,1 \pm 8,2$ years) and control subjects $(29,3 \pm 7,4$ years) in terms of the mean age. The race and ethnicity of groups were also similar. Clinical assessment of AA lesions were performed by determining number of site and size of the lesions and classification according to severity of alopecia tool into: $\mathrm{S} 0=$ no hair loss, $\mathrm{S} 1=<25 \%$ hair loss, S2 $=25$ $49 \%$ hair loss, S3 $=50-74 \%$ hair loss, S4 $=75-99 \%$ hair loss, S5 $=100 \%$ hair loss [8]. The serum concentration of calcium, phosphorus, total protein, albumin, alkaline phosphatase and parathormon were assayed by standard methods (autoanalyzer, Beckman Coulter LX-20).

\section{Vitamin D concentrations}

Fourty-two of AA patients had sera drawn to determine the concentrations of $25(\mathrm{OH})-\mathrm{D}$ and $1,25(\mathrm{OH})_{2} \mathrm{D}_{3}$. Laboratory testing was performed in the laboratory of biochemistry at Mustafa Kemal University, Turkey. Blood samples were drawn from the antecubital vein by careful vein puncture in a $21 \mathrm{G}$ sterile syringe without stasis at 08.00-10.00 AM after a fasting period of $12 \mathrm{~h}$ and then centrifuged at $4000 \mathrm{~g}$ for $5 \mathrm{~min}$ to separate serum for $25(\mathrm{OH})-\mathrm{D}$ and $1,25(\mathrm{OH})_{2} \mathrm{D}_{3}$.

*Corresponding author: Nigar Yilmaz, MD, Department of Biochemistry, Mugla University Medical School, 48000, Mugla, Turkey, Tel: ++90 252251 1000; Fax: ++90 252223 9280; E-mail: drnigaratilgan@yahoo.com

Received March 28, 2012; Accepted May 28, 2012; Published May 31, 2012

Citation: Yilmaz N, Serarslan G, Gokce C (2012) Vitamin D Concentrations are Decreased in Patients with Alopecia Areata. Vitam Trace Elem 1:105.

Copyright: (C) 2012 Yilmaz N, et al. This is an open-access article distributed under the terms of the Creative Commons Attribution License, which permits unrestricted use, distribution, and reproduction in any medium, provided the original author and source are credited. 
The concentrations of $25(\mathrm{OH})-\mathrm{D}$ and $1,25(\mathrm{OH})_{2} \mathrm{D}_{3}$ were measured by ELISA method (Immunodiagnostic Systems ELISA kit, Biomerieux Microwell System Tektime). The recommendation for 25(OH)-D concentrations were defined as $<50 \mathrm{nmol} / \mathrm{L}$ to be insufficient [9]. We did not apply a certain range for $1,25(\mathrm{OH})_{2} \mathrm{D}_{3}$. Decreased concentrations of $1,25(\mathrm{OH})_{2} \mathrm{D}_{3}$ were defined by concentrations at or below $30 \mathrm{pg} / \mathrm{mL}$ [10].

\section{Statistical Analysis}

Data were analyzed by using a commercially available statistics software package (SPSS for Windows v. 15.0, Chicago, Illinois, USA). Distribution of the variable was analyzed with one sample KolmogrovSmirnov test. All groups showed normal distribution, so that parametric statistical methods were used to analyze the data. One way ANOVA test was performed and post hoc multiple comparisons were made using least-squares differences. Correlation between different parameters was assessed using Pearson's coefficient test. To compare age, gender, comorbidity diseases, calcium, phosphorus, total protein, albumin, alkalen phosphatase and parathormon, the Student t-test was used. Results are presented as mean $\pm \mathrm{SD}$; where $\mathrm{p}<0.05$ was regarded as statistically significant and $<0.001$ highly significant.

\section{Results}

Clinical features of the study and control groups were summarized in Table 1 . There were no statistically significant differences between the two groups with respect to age, gender, BMI, calcium, phosphorus, total protein, albumin, alkaline phosphatase and parathormon. The serum $25(\mathrm{OH})$-D concentrations were significantly lower in AA patients $(33,4$ $\pm 17,7 \mathrm{nmol} / \mathrm{L} ; \mathrm{n}=42)$ than in controls $(51,2 \pm 21.1 \mathrm{nmol} / \mathrm{L}, \mathrm{n}=42)(\mathrm{p}$ $<0.001)$ (Table 2). The concentrations of $25(\mathrm{OH})-\mathrm{D}$ were found to be below $50 \mathrm{nmol} / \mathrm{L}$ in $85 \%$ of patients with $\mathrm{AA}$. The serum concentration of $1,25(\mathrm{OH})_{2} \mathrm{D}_{3}$ in AA patients $(40,5 \pm 12,8 \mathrm{pg} / \mathrm{ml}, \mathrm{n}=42)$ was also significantly lower than in controls $(56 \pm 18,4 \mathrm{pg} / \mathrm{ml}, \mathrm{n}=42)(\mathrm{p}<0.001)$ (Table 2). The concentrations of $1,25(\mathrm{OH})_{2} \mathrm{D}_{3}$ were observed to be lower than $30 \mathrm{pg} / \mathrm{mL}$ in $33 \%$ of patients with AA. No correlation was found between the concentrations of $25(\mathrm{OH})-\mathrm{D}, 1,25(\mathrm{OH})_{2} \mathrm{D}_{3}$ and various clinical parameters including extent of the hair loss patch, disease duration, number of patches and nail involvement. Characteristics of patients with AA are shown in Table 3. We found that 8 (19\%) patients with AA had asthma, pernicious anemia, allergic rhinitis and systemic lupus erythematosus as autoimmune diseases. Family history of autoimmune diseases was reported in $71 \%$ of the subjects.

\section{Discussion}

In the present study, we investigated serum 25(OH)-D and $1,25(\mathrm{OH})_{2} \mathrm{D}_{3}$ concentrations of the patients with AA. To the best of our knowledge, no previous studies were done to evaluate $25(\mathrm{OH})-\mathrm{D}$ and $1,25(\mathrm{OH})_{2} \mathrm{D}_{3}$ concentrations in patients with AA. We showed that $25(\mathrm{OH})-\mathrm{D}$ and $1,25(\mathrm{OH})_{2} \mathrm{D}_{3}$ concentrations were statistically lower in patients with AA than control subjects. In addition, there was assessment of vitamin D concentration in relation to pattern or extent of hair loss in patients with AA. It may depend on the number of SALT subclasses which is rarely in the study.

There is strong evidence indicating that $\mathrm{AA}$ is an autoimmune disorder in which immune system attacks to hair follicles. In addition, lymphocyte infiltration around atrophic hair follicles, elevated concentrations of autoantibodies, cytokine abnormalities shows that AA is an organ-specific autoimmune disorder [11]. However, the cause is not known exactly. The hair follicle is known as a hormone-sensitive organ. Recently, vitamin D is a prohormone that has a crucial role in

\begin{tabular}{|l|c|c|c|}
\hline & AA & Control & p value \\
\hline Age (years) & $(\mathrm{n}=42)$ & $(\mathrm{n}=42)$ & \\
\hline Sex (F/M) & $30.8 \pm 8.2$ & $29,3 \pm 7,4$ & 0,31 \\
\hline Calcium (mg/dl) & $28 / 14$ & $29 / 13$ & 0,81 \\
\hline Phosphorus (mg/dl) & $8,4 \pm 0,5$ & $8,3 \pm 0,3$ & 0,44 \\
\hline Total protein (g/dl) & $3,4 \pm 0,6$ & $3,4 \pm 0,3$ & 0,94 \\
\hline Albumin (g/dl) & $6,8 \pm 0,5$ & $6,9 \pm 0,3$ & 0,30 \\
\hline Parathormon (pg/dl) & $4,1 \pm 0,2$ & $4,1 \pm 0,2$ & 0,88 \\
\hline Alkaline phosphatase (Iu/L) & $27,5 \pm 12,5$ & $28,0 \pm 11$ & 0,85 \\
\hline Comorbidities $\mathrm{n}(\%)$ & $63,3 \pm 17,5$ & $61,1 \pm 13,6$ & 0,51 \\
\hline Asthma & $1(\% 2,3)$ & $0(0 \%)$ & $<0.001$ \\
\hline Pernicious anemia & $5(\% 11,9)$ & $0(0 \%)$ & $<0.001$ \\
\hline Allergic rhinitis & $1(\% 2,3)$ & $0(0 \%)$ & $<0.001$ \\
\hline Lupus erythematosus & $1(\% 2,3)$ & $0(0 \%)$ & $<0.001$ \\
\hline
\end{tabular}

F/M: female to male, $p$ value is for comparison between control and study population.

Table 1: Comparison of the clinical and laboratory characteristics of the patients with $\mathrm{AA}$ and healthy controls.

\begin{tabular}{|l|c|c|c|}
\hline & AA & Control & P value \\
\hline 25(OH)-D vitamin (nmol/l) & $(\mathrm{n}=42)$ & $(\mathrm{n}=42)$ & \\
\hline $\mathbf{1 , 2 5}(\mathrm{OH}) 2 \mathrm{D} 3$ vitamin(pg/ml) & $40,4 \pm 17,7$ & $51,2 \pm 21,1$ & $<0.001$ \\
\hline
\end{tabular}

25(OH)-D: 25-hydroxyvitamin $\mathrm{D}$ levels and $1,25(\mathrm{OH})_{2} \mathrm{D}_{3}: 1,25$ dihydroxyvitamin $\mathrm{D} 3$. $P$ value is for comparison between control and study population.

Table 2: Comparison of the $25(\mathrm{OH})$ - Dand 1,25 D levels of the patients with AA and controls.

\begin{tabular}{|l|c|c|}
\hline AA & Frequency & $\%$ \\
\hline Onset & & \\
\hline Old & 11 & 26,1 \\
\hline New & 31 & 73,8 \\
\hline SALT subclasses & & \\
\hline $\mathrm{S}_{1}$ & 30 & 71,4 \\
\hline $\mathrm{S}_{2}$ & 6 & 14,2 \\
\hline $\mathrm{S}_{3}$ & 3 & 7,4 \\
\hline $\mathrm{S}_{4}$ & 2 & 4,7 \\
\hline $\mathrm{S}_{5}$ & 1 & 2,3 \\
\hline Pattern of scalp hair loss & & \\
\hline Patchy & 34 & 80,9 \\
\hline Ophiasis & 6 & 14,2 \\
\hline Totalis & 2 & 4,7 \\
\hline Patient and family medical history & & 35,7 \\
\hline Thyroid disease & 15 & 50 \\
\hline Diabetes & 21 & 23,8 \\
\hline Asthma & 10 & 4,7 \\
\hline Psoriasis & 2 & 2,3 \\
\hline Atopic dermatit & 1 & 2,3 \\
\hline Vitiligo & 1 & 2,3 \\
\hline Pernicious anemia & 1 & \\
\hline Rheumatoid arthritis & & \\
\hline & & \\
\hline
\end{tabular}

Table 3: Characteristics of patients with AA

immune regulation, cell differentiation and growth. The $1,25(\mathrm{OH})_{2} \mathrm{D}_{3}$ acts by binding the specific VDR which is strongly expressed in key structures of hair follicles. It was showed that the lack of VDR leads to the hair follicle growth [12]. Vitamin D defiency may be of special stimulating innate immunity in the setting of AA.

Furthermore, it was previously indicated that a history of autoimmune diseases including thyroid disorders, pernicious anemia, 
psoriasis, and vitiligo are also risk factors for AA [13] We found that 8 (19\%) patients with AA also had other autoimmune diseases. In the study, we found that AA has features of comorbidity autoimmune illness and family autoimmune history. Similarly, Kilic et al. showed that $17(13,6 \%)$ patients with AA had other autoimmune diseases [14]. The association between AA and other autoimmune diseases was also described well, previously [15]. It is possible that vitamin $\mathrm{D}$ concentrations in patients with AA may associate with increased secondary autoimmune disorders. Similarly, numerous studies reported vitamin $\mathrm{D}$ concentrations are associated with some autoimmune diseases. It was reported that $1,25(\mathrm{OH})_{2} \mathrm{D}_{3}$ effects the immune system and low concentrations are associated with autoimmune disorders [16]. The associations between serum concentrations of 25(OH)-D and various autoimmune diseases such as multiple sclerosis, sistemic lupus erythematosus, romatoid arthritis were described [17]. It was also suggested that the role of vitamin D may be crucial in prevention and possible treatment of these diseases [18]. Besides, decreased concentrations of the biologically active form of vitamin $\mathrm{D} ; 1,25(\mathrm{OH})_{2} \mathrm{D}_{3}$ have been reported in many autoimmune diseases including systemic lupus erythematosus [19-21]. Recently, it was found that $25(\mathrm{OH})-\mathrm{D}$ deficiency is a risk factor for vitiligo vulgaris which is an autoimmune depigmentation skin disorder. 25(OH)-D concentrations are important since circulating $25(\mathrm{OH})-\mathrm{D}$ often accurately reflects vitamin $\mathrm{D}$ status. The serum concentration of $25(\mathrm{OH})-\mathrm{D}$ is a sensitive measure of the autoimmune conditions. The determination method of 25(OH)-D deficiency is variable [22]. Multiple studies showed increase in prevalence of autoimmune disorders when vitamin $\mathrm{D}$ deficiency was present. It was also reported that decreased concentrations of vitamin D were associated with active Behcet disease [23].

The effect of $1,25(\mathrm{OH})_{2} \mathrm{D}_{3}$ to inhibit proliferation has been described in modulation of growth and differentiation status of lymphocytes and functions of a variety of cells [24,4]. In addition, use of $1,25(\mathrm{OH})_{2} \mathrm{D}_{3}$ concentrations as a clinical marker in autoimmune conditions was reported and it was found to have positive effects in the treatment of autoimmune diseases [25]. However, little is known about the association of $1,25(\mathrm{OH})_{2} \mathrm{D}_{3}$ and AA. The potential to develop autoimmune conditions such as AA may be related to vitamin D deficiency. It was found that serum $1,25(\mathrm{OH})_{2} \mathrm{D}_{3}$ concentrations were lower in patients with AA than the healthy subjects. $1,25(\mathrm{OH})_{2} \mathrm{D}_{3}$ concentrations may be used an indicator in the diagnosis of AA. It was showed that $1,25(\mathrm{OH})_{2} \mathrm{D}_{3}$ effects the immune system and decreased concentrations are related to autoimmune diseases. Moreover, beneficial effects of vitamin $\mathrm{D}$ supplementation on autoimmune conditions are known and the effects of vitamin $\mathrm{D}$ are mediated by the active form of vitamin $\mathrm{D}$ termed $1,25(\mathrm{OH})_{2} \mathrm{D}_{3}$ [23]. In the immune system, $1,25(\mathrm{OH})_{2} \mathrm{D}_{3}$ targets various immune cells, especially $\mathrm{T}$ lymphocytes and B-lymphocytes, shapes of cytokine secretion patterns and modulates both innate and adaptive immune responses. $1,25(\mathrm{OH})_{2} \mathrm{D}_{3}$ was shown to have a role as an immunomodulator [25]. In addition, Peterlik et al. suggests that there is increased risk for Th1mediated autoimmune diseases upon vitamin $\mathrm{D}$ deficiency and also the $1,25(\mathrm{OH})_{2} \mathrm{D}_{3}$ mediated attenuation of pathological Th1 immune responses is impaired in immune-mediated diseases [26].

In conclusion, we have shown that $25(\mathrm{OH})-\mathrm{D}$ and $1,25(\mathrm{OH})_{2} \mathrm{D}_{3}$ concentrations were significantly decreased in patients with AA compared control group and it was not correlated with pattern or extent of hair loss in patients with AA. Although the etiology of AA is still unresolved, the data obtained from our results support evidence of an association between lower vitamin D concentrations and developing of AA.

\section{Acknowledgement}

The study was supported by the Scientific Research Project Unit of Mustafa Kemal University (BAP-TU- 1005 M 0131).

\section{References}

1. Baeke F, van Etten E, Gysemans C, Overbergh L, Mathieu C (2008) Vitamin $D$ signaling in immune-mediated disorders: Evolving insights and therapeutic opportunities. Mol Aspects Med 29: 376-387.

2. Deluca HF, Cantorna MT (2001) Vitamin D: its role and uses in immunology. Faseb J 15: 2579-2585.

3. Arnson $Y$, Amital H, Shoenfeld $Y$ (2007) Vitamin D and autoimmunity: new aetiological and therapeutic considerations. Ann Rheum Dis 66: 1137-1142.

4. Baeke F, Takiishi T, Korf H, Gysemans C, Mathieu C (2010) Vitamin D modulator of the immune system. Curr Opin Pharmacol 10: 482-496.

5. Shoenfeld N, Amital H, Shoenfeld $Y$ (2009) The effect of melanism and vitamin $\mathrm{D}$ synthesis on the incidence of autoimmune disease. Nat Clin Pract Rheumatol 5: 99-105.

6. Adams JS, Liu PT, Chun R, Modlin RL, Hewison M (2007) Vitamin D in defense of the human immune response. Ann N Y Acad Sci 1117: 94-105.

7. Abdel Hafez HZ, Mahran AM, Hofny EM, Attallah DA, Sayed DS, et al. (2009) Alopecia Areata is not associated with Helicobacter pylori. Indian J Dermatol 54: 17-19.

8. Olsen EA, Hordinsky MK, Price VH, Roberts JL, Shapiro J, et al. (2004) Alopecia areata investigational assessment guidelines--Part II. National Alopecia Areata Foundation. J Am Acad Dermatol 51: 440-447.

9. Haroon M, Bond U, Quillinan N, Phelan MJ, Regan MJ (2011) The prevalence of vitamin $\mathrm{D}$ deficiency in consecutive new patients seen over a 6-month period in general rheumatology clinics. Clin Rheumatol 30: 789-794.

10. Platz EA, Hankinson SE, Hollis BW, Colditz GA, Hunter DJ, et al. (2000) Plasma 1,25-dihydroxy- and 25-hydroxyvitamin $D$ and adenomatous polyps of the distal colorectum. Cancer Epidemiol Biomarkers Prev 9: 1059-1065.

11. Brajac I, Kastelan M, Perisa D, Simonić E, Stojnić-Sosa L, et al. (2010) Treatment of alopecia areata: modern principles and perspectives. Lijec Vjesn 132: $365-369$

12. Reichrath J, Rech M, Moeini M, Meese E, Tilgen W, et al. (2007) In vitro comparison of the vitamin $\mathrm{D}$ endocrine system in 1,25(OH)2D3-responsive and -resistant melanoma cells. Cancer Biol Ther 6: 48-55

13. Goh C, Finkel M, Christos PJ, Sinha AA (2006) Profile of 513 patients with alopecia areata: associations of disease subtypes with atopy, autoimmune disease and positive family history. J Eur Acad Dermatol Venereol 20: 10551060.

14. Kiliç S, Ersoy F, Sanal O, Türkbay D, Tezcan I (1999) Alopecia universalis in a patient with common variable immunodeficiency. Pediatr Dermatol 16: 305307.

15. Ahmed I, Nasreen S, Bhatti R (2007) Alopecia areata in children. J Col Physicians Surg Pak. 170: 587-590

16. Ersoy-Evans S (2010) Commentary: Vitamin D and autoimmunity: is there an association? J Am Acad Dermatol 62: 942-944.

17. Koizumi T, Nakao Y, Matsui T, Nakagawa T, Matsuda S, et al. (1985) Effects of corticosteroid and 1, 24Rdihydroxy- vitamin D3 administration on lymphoproliferation and autoimmune disease in MRL/MP-Ipr/lpr mice. Int Arch Allergy Appl Immunol 77: 396-404.

18. Bartley J (2010) Vitamin D: emerging roles in infection and immunity. Expert Rev Anti Infect Ther 8: 1359-1369.

19. Van Etten E, Mathieu C (2005) Immunoregulation by 1,25-dihydroxyvitamin D3 Basic concepts. J Steroid Biochem Mol Biol. 97: 93-101.

20. Huisman AM, White KP, Algra A, Harth M, Vieth R, et al. (2001) Vitamin D levels in women with systemic lupus erythematosus and fibromyalgia. J Rheumatol 28: 2535-2539.

21. Becker A, Fischer R, Schneider M (2001) Bone density and 25-OH vitamin $\mathrm{D}$ serum level in patients with systemic lupus erythematosus. Rheumatol 60 : 352-358.

22. Blaney GP, Albert PJ, Proal AD (2009) Vitamin D metabolites as clinica markers in autoimmune and chronic disease. Ann N Y Acad Sci 1173: 384-390. 
Citation: Yilmaz N, Serarslan G, Gokce C (2012) Vitamin D Concentrations are Decreased in Patients with Alopecia Areata. Vitam Trace Elem 1:105.

Page 4 of 4

23. Hamzaoui K, Ben Dhifallah I, Karray E, Sassi FH, Hamzaoui A (2010) Vitamin D modulates peripheral immunity in patients with Behçet's disease. Clin Exp Rheumatol 28: S50-S57.

24. Dusso AS, AJ Brown, Slatopolsky E (2005) Vitamin D. Am J Physiol 289: 8-28.

25. May E, Asadullah K, Zügel U (2004) Immunoregulation through 1,25-dihydroxyvitamin D3 and its analogs. Curr Drug Targets Inflamm Allergy 3: 377-393.

26. Peterlik M, Cross HS (2005) Vitamin D and calcium deficits predispose for multiple chronic diseases. Eur J Clin Invest 35: 290-304. 